\title{
Study and Order of a Medium Power Wind Turbine Conversion Chain Connected to Medium Voltage Grid
}

\author{
Abdelhafid Guediri \\ Faculty of Technology \\ VTRS Laboratory \\ The University of El Oued \\ El Oued, Algeria \\ abdelhafid-guediri@univ-eloued.dz
}

\author{
Abdelkarim Guediri \\ Faculty of Technology \\ VTRS Laboratory \\ The University of El Oued \\ El Oued, Algeria \\ karim_elect@yahoo.fr
}

\begin{abstract}
In this article, we will study a system consisting of a wind turbine operating at a variable wind speed and a two-feed asynchronous machine (DFIG) connected to the grid by the stator and fed by a transducer at the rotor side. The conductors are separately controlled for active and reactive power flow between the stator (DFIG) and the network, which is achieved using conventional PI and fuzzy logic. The proposed controllers generate reference voltages for the rotor to ensure that the active and reactive powers reach the required reference values, in order to ensure effective tracking of the optimum operating point and to obtain the maximum electrical power output. System modeling and simulation were examined with Matlab. Dynamic analysis of the system is performed under variable wind speed. This analysis is based on active and reactive energy control. The results obtained show the advantages of the proposed intelligent control unit.
\end{abstract}

Keywords-Doubly Fed Induction Generator (DFIG); active and reactive control; fuzzy management; fuzzy PI controller; variable speed wind turbine

\section{INTRODUCTION}

Variable speed wind generators are more attractive than fixed speed systems due to their efficiency, their quality in the power output, and their dynamic performance in the occurrence of network faults. The majority of wind diversion systems are equipped with Doubly Fed Induction Generators (DFIGs) [1]. Under ideal control conditions, at different wind speeds, the system can extract maximum energy. Wind speed measuring instruments are used and the command is derived for the required optimum speed turbine [2]. However, anemometers can increase the cost of the wind transmission system and reduce its reliability [3]. Several turbine control technologies have been developed to improve the energy output for a specific wind speed. Some variable speed techniques require a strategy for estimating wind velocity, which is very difficult under highly variable wind conditions [4]. Three types of PI regulators are offered. In this paper, a fuzzy logic controller is proposed to control the DFIG speed for the maximum operating point to track force for a wide range of wind speeds.

\section{WIND TURBINE MODEL}

A DFIG wind turbine consists of a variable speed turbine, a generator and a gearbox $[5,6]$. The main objective of the turbine is to convert wind power to mechanical power on its shaft. The relationship between mechanical power, $P_{\text {mech }}$ and rotor speed, $w$ is described as [7]:

$$
P_{\text {mech }}=\frac{1}{2} C_{p} \rho \pi R^{2} V^{3}
$$

where $\rho$ corresponds to the density of the air and $R$ to the radius of the turbine fan respectively. The force modulus can be described because the fraction of the mechanical strength extracted from the total force to be obtained from the wind is specific to each turbine [8]. The power factor $C p$ is generally known as the pause ratio characteristic [9].

\section{MODELING OF THE DFIG}

The DFIG electrical state can be modeled using the Park Transformation as follows [10]:

$$
\left\{\begin{array}{c}
V_{s d}=R_{s} I_{s d}+\frac{d \varphi_{s d}}{d t} \\
V_{s q}=R_{s} I_{s q}+\omega_{s} \varphi_{s d} \\
V_{r d}=R_{r} I_{r d}+\frac{d \varphi_{r d}}{d t}-\left(\omega_{s}-\omega\right) \varphi_{r q} \\
V_{r q}=R_{r} I_{r q}+\frac{d \varphi_{r q}}{d t}+\left(\omega_{s}-\omega\right) \varphi_{r d}
\end{array}\right.
$$

To obtain separate control over the stator reactive and active forces, the DFIG model is required to express all quantities. This is in accordance with the concept of stator flow direction and the assumption that the stator resistance is small compared to the stator reactance of a DFIG of medium and high power volume, where the stator flux can be computed as [11]:

$$
\left\{\begin{array}{c}
P_{S}=-V_{s} \frac{M}{L_{s}} I_{r q} \\
Q_{s}=\frac{V_{s} \varphi_{S}}{L_{S}}-\frac{V_{s} M}{L_{S}} I_{r d}
\end{array}\right.
$$

The electromagnetic torque is expressed as:

Corresponding author: Abdelhafid Guediri 


$$
C_{e m}=-p \frac{M}{L_{s}} \varphi_{s} I_{r q}
$$

\section{SYSTEM DESCRIPTION}

The first DFIG configuration used in this paper is shown in Figure 1. By means of a gearbox and a coupling shaft mechanism the wind turbine is mechanically connected with the DFIG [12]. The wound-rotor induction generator is fed to the stator and rotor from each element. The stator is directly connected to the grid, while the rotor is fed via lower back to another four-quadrant PWM power converter (RSC and GSC) connected with the use of a battery inside the direct current link condenser [13].

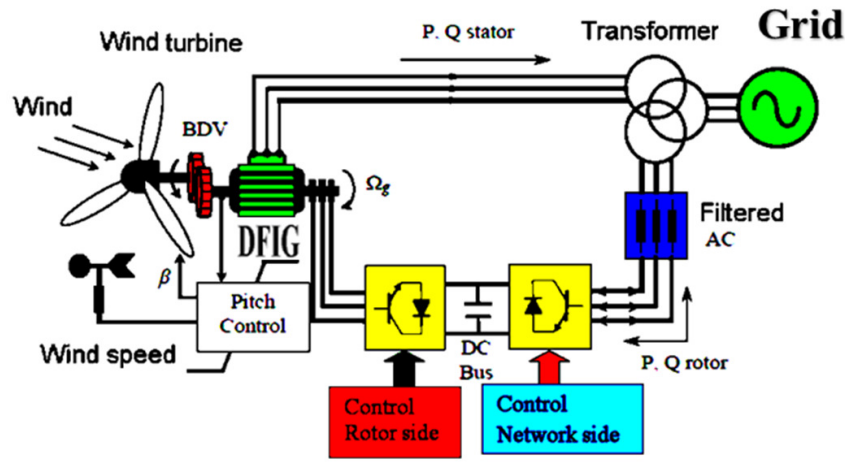

Fig. 1. DFIG-based wind conversion system.

Figure 2 displays a schematic diagram of an ordinary conversion [14]. Figure 3 shows the forces between DFIG, converters, and grid. The rotor aspect converter guarantees a decoupled lively and reactive stator power control, $P s$ and $Q s$, consistent with the reference torque introduced via the Maximum Power Point Tracking (MPPT) control. The grid facet converter manipulates the electricity drift trade with the grid through. The rotor maintains the direct current bus at a steady voltage state and enforces the reactive energy QL at zero [15].

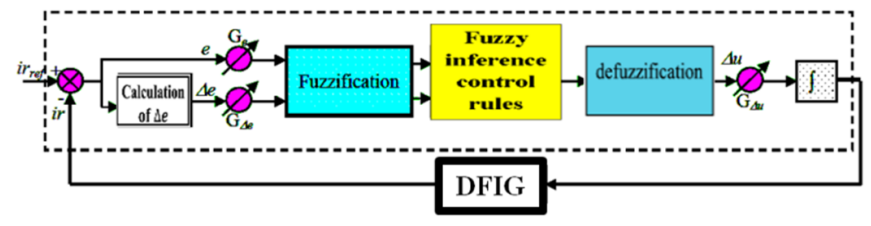

Fig. 2. Block diagram of the fuzzy controller.
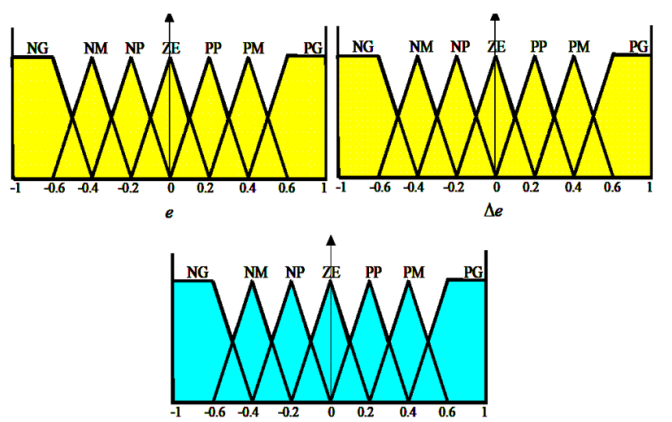

Fig. 3. Membership functions used by the controller.
TABLE I. RULE TABLE OF THE FUZZY CONTROLLER

\begin{tabular}{|c|c|c|c|c|c|c|c|c|}
\hline \multicolumn{2}{|c}{$\Delta \boldsymbol{U}$} & \multicolumn{7}{|c|}{ E } \\
\cline { 2 - 9 } & NG & NM & NP & EZ & PP & PM & PG \\
\hline \multirow{4}{*}{$\Delta \mathbf{e}$} & NG & NG & NG & NG & NM & NP & NP & EZ \\
\cline { 2 - 9 } & NM & NG & NM & NM & NM & NP & EZ & PP \\
\cline { 2 - 9 } & NP & NG & NM & NP & NP & EZ & PP & PM \\
\cline { 2 - 9 } & EZ & NG & NM & NP & EZ & PP & PM & PG \\
\cline { 2 - 9 } & PP & NM & NP & EZ & PP & PP & PM & PG \\
\cline { 2 - 9 } & PM & NP & EZ & PP & PM & PM & PM & PG \\
\cline { 2 - 9 } & PG & EZ & PP & PP & PM & PG & PG & PG \\
\hline
\end{tabular}

\section{ADJUSTMENT OF THE ROTOR CURRENTS OF THE DFIG}

We will now use the same diagram of the vector control except that this time the rotor current regulators are fuzzy regulators (Figure 4).

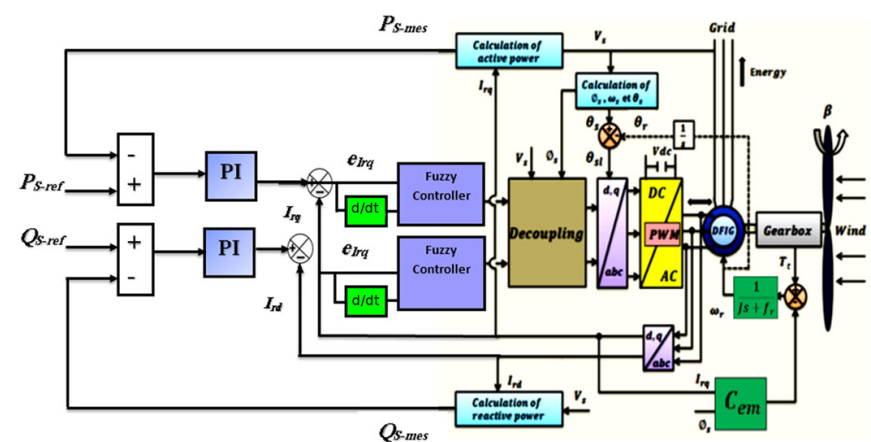

Fig. 4. Block diagram of the DFIG fuzzy-PI regulator of speed for supply of power to the electrical grid.

The two current regulators are of the same type (seven-class Mamdani-type regulator), and have the same membership functions.

\section{RESULTS AND DISCUSSION}

For the robustness tests of the control by fuzzy regulators, we studied the influence of the variation of the rotor resistance and own and mutual inductance on the performance of control. Our wind power system (turbine+DFIG) is controlled by fuzzy regulators. The starting is no-load then a reference active power is applied:

- Between $\mathrm{t}=0.2 \mathrm{~s}$ and $\mathrm{t}=0.6 \mathrm{~s}$ negative scale $\left(\mathrm{P}_{\text {ref }}=-20000 \mathrm{~W}\right)$.

- Between $\mathrm{t}=0.6 \mathrm{~s}$ and $\mathrm{t}=1 \mathrm{~s}\left(\mathrm{P}_{\text {ref }}=-10000 \mathrm{~W}\right)$.

- Reactive power: Between $\mathrm{t}=0 \mathrm{~s}$ and $\mathrm{t}=1 \mathrm{~s}$ step $\left(Q_{\text {ref }}=0 \mathrm{VAR}\right)$

Figures 5-13 show the performance of the reactive and active stator power PI- fuzzy control applied to the DFIG. In Figures 6 and 7 we observe that the direct and quadrature components of the stator and rotor currents follow their reference values. In view of these results, better tracking of the fuzzy regulator compared to that of the PI regulator is achieved. Fuzzy regulators do not generate any overshoot, particularly at transient. For the other performances, they are almost similar to that of the PI regulator. Figure 12 shows the waveform of the stator voltage and current. 


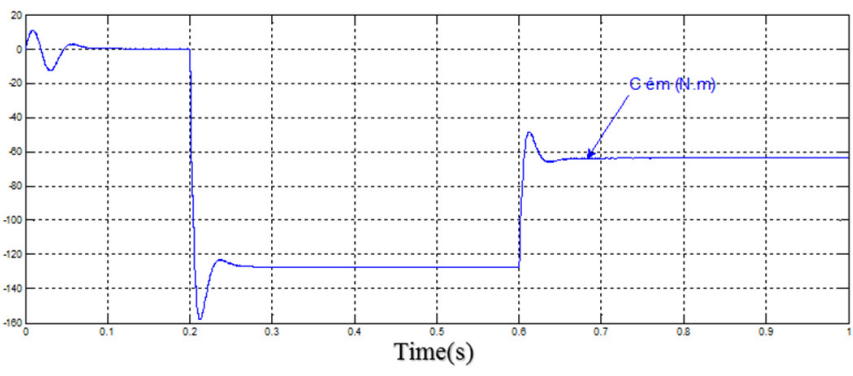

Fig. 5. Electromagnetic torque.

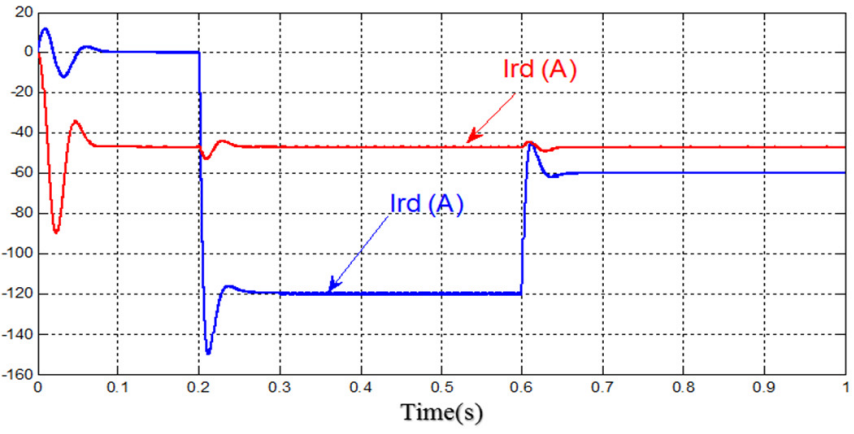

Fig. 6. Direct and quadrature rotor currents.

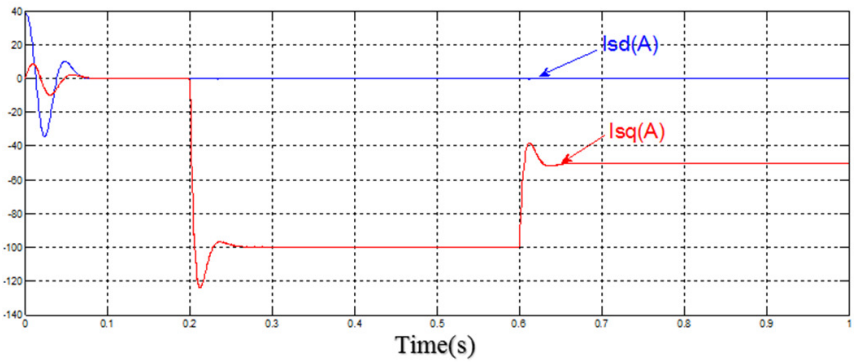

Fig. 7. Direct and quadrature stator currents.

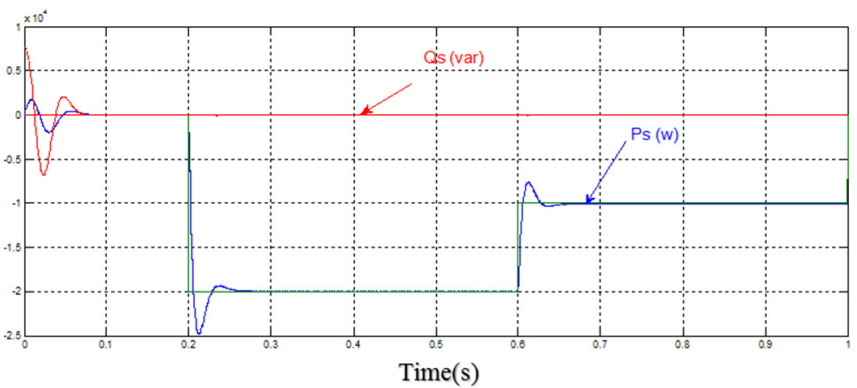

Fig. 8. Stator active power (W) and reactive power (VAR)

We can notice that the stator voltage is equal to that of the network, while the waveform of the current is related to that of the active power and the reactive power. The stator current and voltage are in phase opposition, as shown in Figure 12. This means that the stator active power is sent from the generator to the network. Note that the stator voltage and current waveforms are independent of the wind speed profile. Tuning by fuzzy logic may override tuning by PI with respect to the quality of the dynamic response of the system. Indeed, the latter further reduces the response time by producing a limited overshoot accompanied by weak oscillations around the setpoint in steady state. The precision is not as good as that of a PI regulator where the integral action eliminates the static error. This suggests the combination of two types of regulators: a fuzzy regulator for the transient regime and a PI regulator for the steady state.

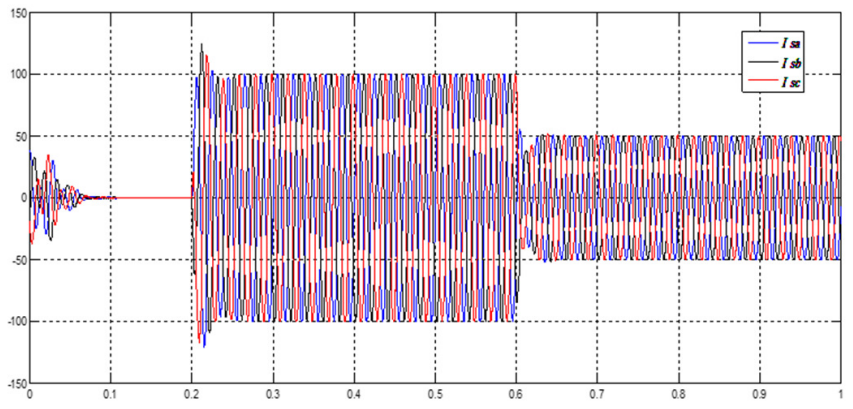

Time(s)

Fig. 9. Three-phase stator current.

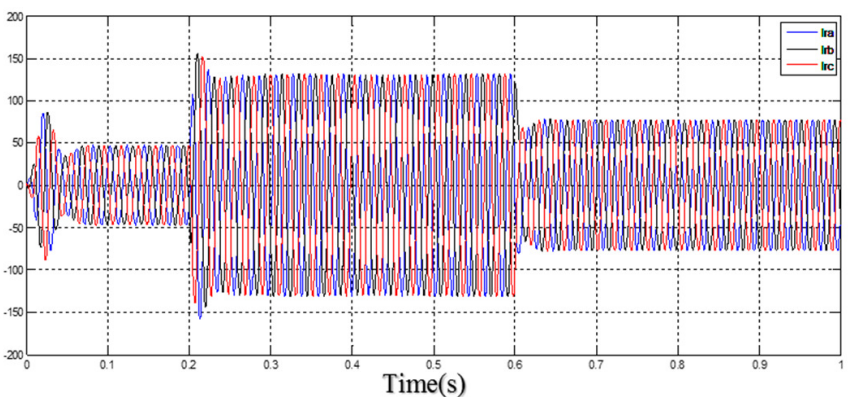

Fig. 10. Three-phase rotor current.

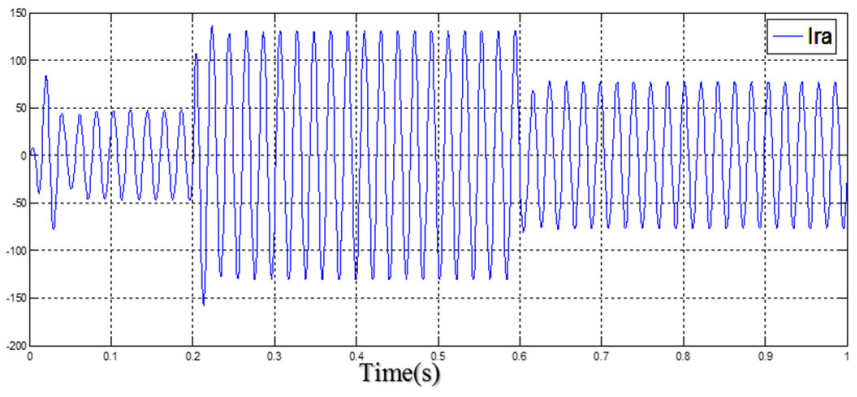

Fig. 11. Current per rotor phase.

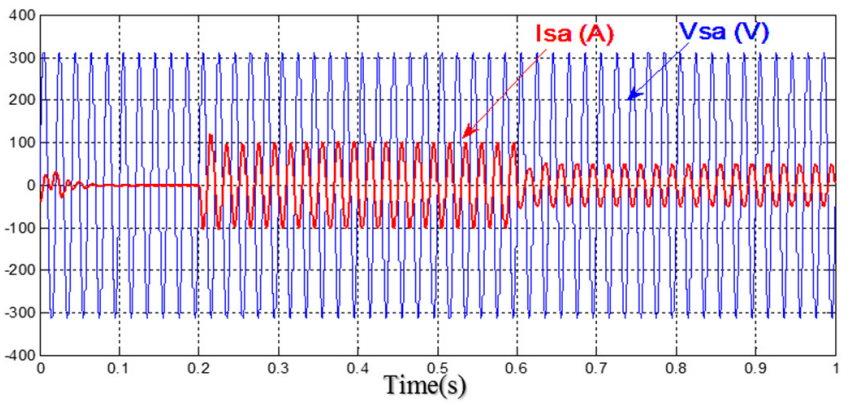

Fig. 12. The stator current and voltage. 


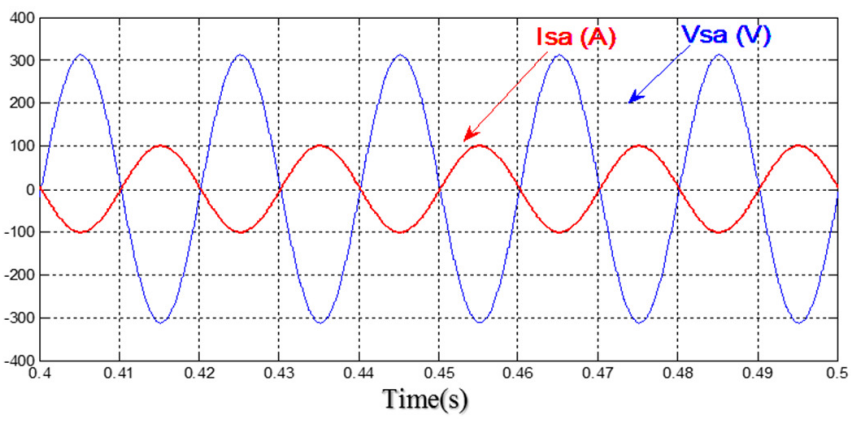

Fig. 13. Focus on stator current and voltage.

\section{CONCLUSION}

In this paper, the technique of fuzzy logic has been explored. A fuzzy logic controller using the concept of offline decision table was installed in the vector control for a asynchronous dual power machine (DFIG). This choice of command was justified by the ability of fuzzy logic to handle the imprecise, the uncertain, and the vague. The obtained results show that the FLC has very satisfactory tracking performance. It has improved the dynamics of the rotor currents compared to that of the adjustment by PI. The major problem in designing an FLC is the choice of membership functions for the input and output variables, which is generally done thanks to the expertise of the process. However, a fuzzy system is difficult to grasp. Its control and adjustment can be relatively long. Sometimes it is a lot more of a trial and error procedure than a real reflection. Fuzzy logic therefore lacks a high-performance learning medium for solving a fuzzy system.

\section{APPENDIX}

PARAMETERS OF THE 1.5MW DFIG

\begin{tabular}{|c|l|c|}
\hline Symbol & \multicolumn{1}{|c|}{ Parameters } & Value \\
\hline $\mathrm{Pn}$ & Rated Power & $1.5 \mathrm{MW}$ \\
\hline $\mathrm{Vs}$ & Stator Voltage & $300 \mathrm{~V}$ \\
\hline $\mathrm{Fs}$ & Stator Frequency & $50 \mathrm{~Hz}$ \\
\hline $\mathrm{Rs}$ & Stator Resistance & $0.012 \Omega$ \\
\hline $\mathrm{Ls}$ & Stator Leakage Inductance & $0.0205 \mathrm{H}$ \\
\hline $\mathrm{Rr}$ & Rotor Resistance & $0.021 \Omega$ \\
\hline $\mathrm{Lr}$ & Rotor Leakage Inductance & $0.0204 \mathrm{H}$ \\
\hline $\mathrm{Lm}$ & Mutual Inductance & $0.0169 \mathrm{H}$ \\
\hline $\mathrm{P}$ & Poles Pairs Number & 2 \\
\hline $\mathrm{J}$ & Rotor Inertia & $1000 \mathrm{Kg} \cdot \mathrm{m}^{2}$ \\
\hline
\end{tabular}

PARAMETERS OF THE TURBINE

\begin{tabular}{|c|l|c|}
\hline Symbol & \multicolumn{1}{|c|}{ Parameters } & Value \\
\hline $\mathrm{R}$ & Blade Radius & $35.25 \mathrm{~m}$ \\
\hline $\mathrm{N}$ & Number of Blades & 3 \\
\hline $\mathrm{G}$ & Gearbox ratio & 90 \\
\hline $\mathrm{J}$ & Moment of inertia & $\mathrm{Kg} \cdot \mathrm{m}^{2}$ \\
\hline $\mathrm{fv}$ & Viscous friction coefficient & $0.0024 \mathrm{~N} \cdot \mathrm{m} \cdot \mathrm{s}^{-1}$ \\
\hline $\mathrm{V}$ & Nominal Wind Speed & $16 \mathrm{~m} / \mathrm{s}$ \\
\hline $\mathrm{Vd}$ & Cut-in Wind Speed & $4 \mathrm{~m} / \mathrm{s}$ \\
\hline $\mathrm{Vm}$ & Cut-out Wind Speed & $25 \mathrm{~m} / \mathrm{s}$ \\
\hline
\end{tabular}

\section{REFERENCES}

[1] A. K. Guediri and D. Ben Attous, "Fuzzy control of a doubly fed asynchronous machine (DFAM) generator driven by a wind turbine modeling and simulation," International Journal of System Assurance Engineering and Management, vol. 8, no. 1, pp. 8-17, Jan. 2017, https://doi.org/10.1007/s13198-014-0256-z.

[2] W. Guo, F. Liu, D. He, J. Si, R. Harley, and S. Mei, "Reactive power control of DFIG wind farm using online supplementary learning controller based on approximate dynamic programming," in 2014 International Joint Conference on Neural Networks (IJCNN), Beijing, China, Jul. 2014, pp. 1453-1460, https://doi.org/10.1109/IJCNN.2014. 6889871.

[3] S. A. E. M. Ardjoun and M. Abid, "Fuzzy sliding mode control applied to a doubly fed induction generator for wind turbines," Turkish Journal of Electrical Engineering and Computer Sciences, vol. 23, no. 6, pp. 1673-1686, Nov. 2015, https://doi.org/10.3906/elk-1404-64.

[4] J. Yang, S. Dongran, H. Han, P. Tong, and L. Zhou, "The integrated control of fuzzy logic and model-based approach for variable-speed wind turbine," Turkish Journal of Electrical Engineering and Computer Sciences, vol. 23, no. 6, pp. 1715-1734, Jan. 2015, https://doi.org/ 10.3906/elk-1403-295.

[5] O. P. Bharti, R. K. Saket, and S. K. Nagar, "Controller Design For DFIG Driven By Variable Speed Wind Turbine Using Static Output Feedback Technique," Engineering, Technology \& Applied Science Research, vol. 6, no. 4, pp. 1056-1061, Aug. 2016, https://doi.org/10.48084/etasr.697.

[6] P. D. Chung, "Retaining of Frequency in Micro-grid with Wind Turbine and Diesel Generator," Engineering, Technology \& Applied Science Research, vol. 8, no. 6, pp. 3646-3651, Dec. 2018, https://doi.org/ 10.48084/etasr.2413

[7] H. Bassi and Y. A. Mobarak, "State-Space Modeling and Performance Analysis of Variable-Speed Wind Turbine Based on a Model Predictive Control Approach," Engineering, Technology \& Applied Science Research, vol. 7, no. 2, pp. 1436-1443, Apr. 2017, https://doi.org/ 10.48084/etasr.1015.

[8] "Wind in Numbers," Global Wind Energy Council. https:/gwec.net/global-figures/wind-in-numbers/ (accessed Jun. 01, 2021).

[9] K. Siraj, H. Siraj, and M. Nasir, "Modeling and control of a doubly fed induction generator for grid integrated wind turbine," in 2014 16th International Power Electronics and Motion Control Conference and Exposition, Antalya, Turkey, Sep. 2014, pp. 901-906, https://doi.org/10.1109/EPEPEMC.2014.6980613.

[10] I. Yaichi, A. Semmah, P. Wira, and Y. Djeriri, "Super-twisting Sliding Mode Control of a Doubly-fed Induction Generator Based on the SVM Strategy," Periodica Polytechnica Electrical Engineering and Computer Science, vol. 63, no. 3, pp. 178-190, Jun. 2019, https://doi.org/ 10.3311/PPee. 13726.

[11] Z. Kara and K. Barra, "Hybrid Controller for Variable Speed Wind Energy Conversion System with Slip Energy Recovery Using Matrix Converter Topology," Periodica Polytechnica Electrical Engineering and Computer Science, vol. 59, no. 4, pp. 160-174, Dec. 2015, https://doi.org/10.3311/PPee.8507.

[12] S. Chikha, "Active and Reactive Power Management of Wind Farm Based on a Six Leg Tow Stage Matrix Converter Controlled by a Predictive Direct Power Controller," Iranian Journal of Electrical and Electronic Engineering, vol. 14, no. 3, pp. 245-258, Sep. 2018, https://doi.org/10.22068/IJEEE.14.3.245.

[13] S. Massoum, A. Meroufel, A. Massoum, and P. Wira, "A direct power control of the doubly-fed induction generator based on the SVM Strategy," Elektrotehniski Vestnik/Electrotechnical Review, vol. 84, no. 5, pp. 235-240, Jan. 2017.

[14] H. Benbouhenni, A. Belaidi, and Z. Boudjema, "Sensorless Twelve Sectors Implementation of Neural DPC Controlled DFIG for Reactive and Active Powers Ripples Reduction," Majlesi Journal of Energy Management, vol. 7, no. 2, pp. 13-21, Jun. 2018.

[15] H. Benbouhenni, Z. Boudjema, and A. Belaidi, "A Direct Power Control of the Doubly Fed Induction Generator Based on the Three-Level NSVPWM Technique," International Journal of Smart Grid ijSmartGrid, vol. 3, no. 4, pp. 216-225, Dec. 2019. 